\title{
Economic Impact of Road Traffic Accident on Patients Attending at National Institute of Traumatology \& Orthopedic Rehabilitation (NITOR), Dhaka
}

\author{
Mohoshina Karim ${ }^{1}$, Abdul Wadud Khan ${ }^{2}$, Shayela Farah ${ }^{3}$
}

\begin{abstract}
Background \& objeclives: Road traffic accident (RTA) is now a major, growing public health consern worldwide. In particular, the developing countries including Bangladesh are now experiencing a lot of human miseries and losses in human lives and national properties, due to serious road safety crisis. This study was conducted on the road traffic accident patients in National Institute of Traumatology \& Orthopedic Rehabilitation (NITOR), Dhaka to determine the economic impact of RTA on families.

Methods: The present cross-sectional study was conducted on 55 consecutively admitted cases of road-traffic accident. Data were collected by face to face interview of the patient if he or she is an adult and physically able to provide interview or from the parents or guardians if the patient is a minor or physically not sound to participate in interview.

Result: Majority of the patients (about 73\%) was observed in the age range of 10-30 years with mean age of the patients being 22.3 years (range: $2-44$ years). The next vulnerable age group was $30-40$ years (18.1\%). The victims were predominantly male $(85 \%)$. Over one-fifth $(21.8 \%)$ of the accidents was caused by truck and another one-fifth caused by motor-cycle. Cars and buses were the second leading vehicles to cause the accidents ( $14.5 \%$ and $12.7 \%$ respectively). Other less commonly involved vehicles were CNG, Tempo and Rikshaw and others. Over $45 \%$ of the cases were disabled, $25.4 \%$ cases turned handicapped and $21.8 \%$ suffered from mental stress and shock. In $21.8 \%$ cases the duration of hospital stay was 5-10 days, in $18.2 \%$ cases $10-15$ days and in $20 \%$ cases $<5$ days. The hospital stay for rest of the patients (40\%) was 15-40 days. In more than $90 \%$ of the cases the medicine cost and investigations cost were Taka $<500$ and in about half (49.1\%) of the cases the operation cost was below Taka 2000. These three items together constituted direct cost which incurred Taka $<1000$ in $45.5 \%$ cases and Taka $>10000$ in 10.9\% cases. The average direct cost of injury was Taka 5455. Of the indirect costs, food and transport costs were observed to be Taka $<500$ in 90 and $95 \%$ patients respectively and miscellaneous cost was Taka $<2000$ in $82 \%$ patients. Total indirect cost incurred was Taka $>10000$ in $45.5 \%$ patients, while it was Taka $<2000$ in $1.8 \%$ patients with average cost being Taka 8440 . The average total cost of injury was Taka 13277.
\end{abstract}

Conclusion: The total cost RTA due to direct cost for treatment purpose and indirect cost due to daily wedge losses, economic loss, familial loss and social burden together produce significant impact on the economy of our country.

Key words: Road traffic accident, economic impact

\section{Introduction}

Deaths \& injuries resulting from traffic crashes are major and growing public health problem worldwide. Especially the developing countries are now experiencing lot of human miseries and losses in human lives and national properties, due to serious road safety crisis. Road traffic accident- the leading cause of death by injury and the ninth leading cause of all deaths globally now make up a surprisingly significant portion of the worldwide burden of ill health. ${ }^{1}$ Accidents due to motor vehicles are taking an increasingly larger share in the sum total of fatal accidents. In developed countries, the proportion of deaths from this cause is in general between $25-40 \%$ of that attributable to accidents from all causes. ${ }^{2}$ In developing countries the proportion is usually lower ranging from $10-30 \%{ }^{3}$ Worldwide almost 1.3 million people are killed on the road every year. Another 20 to 50 million are injured. It is interesting to note that over 90 percent of these road accident deaths occur in low- and middleincome countries which account for only 48 percent of the world's registered vehicles. Another study estimated that 1-2 million people are killed in road crashes each year and as many as

Authors' Information:

1. Dr. Mohoshina Karim, MBBS; MPH, Lecturer, Dhaka Community Medical College, Dhaka.

2. Prof. Dr. Abdul Wadud Khan, MBBS(DU), DCM(DU), MPH(USA), Fellow(USA) principal of Dhaka Community Medical College \& Hospital.

3. Dr. Shayela Farah, MBBS; MPH, Asst. Professor, Dept. of Community Medicine, Dhaka Community Medical College, Dhaka. 
50 million are injured, occupying $30-70 \%$ of orthopedic beds in developing countries' hospitals. Children, pedestrians, cyclists and the elderly are among the most vulnerable of road users4. RTA alone account for $22.8 \%$ ( 1.2 million per annum) of the overall deaths among all accidents. Around $88 \%$ of the 1.2 million deaths from RTA occur in developing world, where children \& young people are mostly affected. ${ }^{5}$ This Global Status Report on road traffic accident is truly alarming (reference-37). World Health Organization in 2008 published a global report on road traffic accidents, deaths and injuries, which is the first broad assessment of the status of road safety in 178 countries. The results showed that middle-income countries are less safer than those in high-income countries. While in high-income countries, the study reports that road fatality rates have either stabilized or declined, in poorer countries they have markedly increased and are rising further. If the present trend continues, road-traffic deaths will increase to 2.4 million a year by 2030 with more than 90 per cent of them in developing countries. ${ }^{6}$ The case fatality rate is at least 50 times higher than that in developed countries. Road traffic accidents killing and maiming people are a normal everyday phenomenon in Bangladesh now. According to police record every year 4000 people are killed \& 5000 other injured in transport accidents. But actual figures are at least twice as high, because all accidents are not reported. In total 21,288 accidents were recorded by Road safety cell of BRTA in six years that killed around 17,825 people $\&$ injured more than 20,000 others. The economic impact of road-traffic accident is immense. Direct and indirect costs of road accidents in Bangladesh in current prices are Tk. 5000 crore or 850 million \$US (nearly $2 \%$ of GNP) per year. It is predicted that the situation will further worsen in the coming years. This study is, therefore, aimed to assess the economic impact (direct and indirect cost incurred to RTA) on families of the victims.

\section{Methods}

The cross-sectional study was conducted at National Institute of Traumatology \& Orthopedic Rehabilitation (NITOR), Dhaka over a period of 6 months. Patients of RTA admitted in the Inpatient Department NITOR and also in the Emergency Department between January to June 2010 were the study population. A total of 55 patients were consecutively included in the study. Data were collected by interview of the respondents (if $>18$ years old) or by interview of the parents/guardians if the study participants were minors (if $<18$ years old) or physically unable to give interview using a structured questionnaire containing all the variables of interest. Data were analysed using descriptive statistics.

\section{Result}

This study observed that the trauma cases occurred in between the age of 5 to 44 years. Majority of the patients (about $73 \%$ ) was observed in the age range of $10-30$ years with mean age of the patients being 22.3 years. The next vulnerable age group was $30-40$ years (18.1\%). The victims were predominantly male (85\%) (Table I). In terms of occupation businessmen formed one-third (36.4\%) patients, followed by service holders and students (18.2\%) and cultivators (10.9\%). The injury of moderate severity formed the main bulk (54.5\%) followed by mild injury $(27.3 \%)$ and severe injury (18.2\%). Most (65.5\%) of the victims were conscious at the time of admission (as revealed from the medical history sheet). Over one-fifth (21.8\%) of the accidents were caused by truck and another one-fifth caused by motor-cycle. Cars and buses were the second leading vehicles to cause the accidents ( $14.5 \%$ and $12.7 \%$ respectively). Other less commonly involved vehicles were CNG, Tempo and Rikshaw (Table II). Over $45 \%$ of the cases

Table-I: Distribution of the respondents by their demographic characteristics $(n=55)$.

\begin{tabular}{lcc} 
Demographic characteristics & Frequency & Percentage \\
\hline Age* $^{*}$ group (yrs) & 4 & 7.3 \\
$<10$ & 4 & 7.3 \\
$10-20$ & 19 & 34.6 \\
$20-30$ & 21 & 38.1 \\
$30-40$ & 10 & 18.2 \\
$>40$ & 01 & 1.8 \\
Sex & & \\
Male & 47 & 85.0 \\
Female & 8 & 15.0
\end{tabular}

${ }^{*}$ Mean age $=22.3 \quad 5.2$ years. 
became and Rikshaw (Table II). Over $45 \%$ of the cases became disabled, $25.4 \%$ cases turned handicapped and $21.8 \%$ suffered from mental stress and shock. In $21.8 \%$ cases the duration of hospital stay was 5 to 10 days, in $18.2 \%$ cases 10 to 15 days and in $20 \%$ cases $<5$ days. The hospital stay for rest of the patients (40\%) was 15 to 40 days.

The direct cost items were medicine, investigations and operation cost. In $90 \%$ of the cases the medicine cost and investigations cost were Taka $<500$ and in about half $(49.1 \%)$ of the cases the operation cost was below Taka 2000 (Table III). These three items together incurred Taka $<1000$ in $45.5 \%$ cases and Taka $>10000$ in $10.9 \%$ cases (Table IV). The average direct cost of injury was Taka 5455. The indirect cost items investigated were food, transport and miscellaneous costs. Of them food and transport costs were observed to be Taka $<500$ in 90 and

Table-II: Respondents' distribution by vehicles causing the injury $(n=55)$.

\begin{tabular}{lcc} 
Type of vehicles & Frequency & Percentage \\
\hline Truck & 12 & 21.8 \\
Motorcycle & 12 & 21.8 \\
Car & 08 & 14.5 \\
Bus & 07 & 12.7 \\
CNG & 05 & 9.1 \\
Tempo & 03 & 5.5 \\
Rickshaw & 02 & 3.6 \\
Others & 06 & 3.9
\end{tabular}

Table-III: Direct cost incurred due to injury $(n=55)$.

\begin{tabular}{lcc} 
Direct cost (Taka) & Frequency & Percentage \\
\hline $\begin{array}{l}\text { Medicine cost } \\
<500\end{array}$ & 50 & \\
$500-1000$ & 03 & 90.9 \\
$>1000$ & 02 & 3.5 \\
Investigation cost (Taka) & & \\
$<500$ & 48 & 87.3 \\
$500-1000$ & 04 & 7.3 \\
$>1000$ & 03 & 5.4 \\
Operation cost (Taka) & & \\
$<2000$ & 27 & 49.1 \\
$2000-5000$ & 18 & 32.7 \\
$>5000$ & 10 & 18.2
\end{tabular}

Table-IV: Total direct cost incurred due to injury $(n=55)$.

$\begin{array}{lcc}\text { Total direct cost incurred (Taka) } & \text { Frequency } & \text { Percentage } \\ <1000 & 25 & 45.5 \\ 1000-4000 & 16 & 29.1 \\ 4000-8000 & 07 & 12.7 \\ 8000-10000 & 01 & 1.8 \\ >10000 & 06 & 10.9\end{array}$

95\% patients respectively and miscellaneous cost was Taka $<2000$ in $82 \%$ patients (Table V). Total indirect cost incurred was Taka $>10000$ in 45.5\% patients, while it was Taka $<2000$ in $1.8 \%$ cases with average cost being Taka 8440 . (VI). The average total cost of injury (direct cost plus indirect cost) was Taka 13277 (Table VII).

Table-V: Indirect cost incurred due to injury $(n=55)$.

\begin{tabular}{lcc} 
Indirect cost (Taka) & Frequency & Percentage \\
\hline $\begin{array}{l}\text { Food cost (Taka) } \\
<500\end{array}$ & 50 & \\
$500-1000$ & 04 & 7.9 \\
$>1000$ & 01 & 1.8 \\
Transport cost (Taka) & & \\
$<500$ & 52 & 94.5 \\
$500-1000$ & 02 & 3.7 \\
$>1000$ & 01 & 1.8 \\
Miscellaneous cost (Taka) & & \\
$<2000$ & 45 & 81.8 \\
$2000-5000$ & 05 & 9.1 \\
$>5000$ & 05 & 9.1
\end{tabular}

Table-Vl: Total indirect cost incurred due to injury $(n=55)$

\begin{tabular}{|lcc|}
\hline Total indirect cost incurred (Taka) & Frequency & Percentage \\
\hline$<2000$ & 01 & 1.8 \\
$2000-4000$ & 11 & 20.0 \\
$4000-8000$ & 12 & 21.8 \\
$8000-10000$ & 06 & 10.9 \\
$>10000$ & 25 & 45.5
\end{tabular}

Table-VII: Total cost incurred due to injury $(n=55)$

\begin{tabular}{|lcc|}
\hline Total cost incurred (Taka) & Frequency & Percentage \\
\hline 1000 & 01 & 1.8 \\
$1000-4000$ & 08 & 14.5 \\
$4000-10000$ & 17 & 30.7 \\
$10000-16000$ & 09 & 16.5 \\
$>16000$ & 20 & 36.5
\end{tabular}




\section{Discussion}

In the present study the peak age incidence of the RTA victims was observed between 10-30 years of age. Together they constitute nearly three-quarters (73\%) of the cases. Consistent with these findings, a study conducted in Dhaka Medical College Hospital showed that adolescent and adult comprised $86 \%$ of the casualties. ${ }^{7}$ Another study conducted in NITOR also showed that $58 \%$ of RTA victims were young and early middle-aged ( $21-40$ years of age) ${ }^{8}$

In the present study males outnumbered females indicating that male casualties were 7 times higher than females. This may also be due to the fact that males are more mobile in nature than females or males are engaged in outdoor activities more than their female counterparts. It is more or less similar with findings of Anwaruzzaman et $\mathrm{al}^{9}$ where percentage of affected male was $83 \%$ in the age group of $25-34$ years, and $84 \%$ in all age groups. The most common type of vehicles involved in road-traffic accident were truck and motorcycle. They constituted $24(43.6 \%)$ of total accidents. The other vehicles involved in the accident were car, bus, CNG, tempo and rickshaw.

The main aspect of this study was to find the cost of treatment due to road traffic accident. The cost was calculated as direct and indirect costs. The direct cost involves the costs that were made for treatment purposes, that is for medicine, investigation and operation costs. The indirect cost involves food-cost, transport cost, miscellaneous cost and cost involved for attendance. Out of 55 respondents direct cost involved less than Tk 1000 was for 25(45.5\%), Tk 1000 to 4000 for $16(29.1 \%)$ and more than Tk 10000 for $6(10.9 \%)$ respondents. The indirect cost involved more than Tk 10000 for $25(45.5 \%$ ), Tk 1001-4000 for 11 (20.0\%) respondents. These findings were compared with a study done by Altes \& Perez. ${ }^{10}$ They reported the direct cost for road traffic casualties was very high. These findings were also compared with another study conducted by Reddy et al. ${ }^{11}$ They showed that out of 121 crash victims the net direct cost incurred were Rs. 8,55,644 which is staggeringly high compared to this study. These may be due to the fact that the study was conducted mainly on crash victims (major injury) only.
It is revealed that indirect cost involved was much more than direct cost. As the study was conducted on patients admitted in NITOR which is a Government run facility, there should not be any direct cost involvement for the treatment is free of cost. An overview of the total duration of stay in the hospital showed that in $21.8 \%$ cases the duration of hospital stay was 5 to 10 days, in $18.2 \%$ cases 10 to 15 days and in $20 \%$ cases $<5$ days. The hospital stay for rest of the patients (40\%) was 15 to 40 days. This result is nearly similar to that of another study conducted by Dewan at RIHD, where he showed the distribution of hospital stay as follows: $41.7 \%$ patients stayed for 1-10 days, 23\% cases stayed for 11-20 days. Mishra et al conducted another study showing an average of 12.8 days lost for each case. ${ }^{12}$

The study showed that monthly income of the respondents less than Tk 5000 was $38.2 \%$. The economic cost of road crashes is US\$ 518 billion globally per year; for the developing countries the economic loss due to RTA is about US\$ 100 billion (1-3 percent of GDP, nearly equivalent to double of all overseas development assistance) which adversely affect the victim as well as their family members thus contributing to the persistence of poverty. ${ }^{13}$

In the present study $45.5 \%$ respondents were disabled and $25.4 \%$ were handicapped. National Institute of Traumatology \& Orthopedic Rehabilitation is the only one specialized hospital for the trauma cases in the country. Although there is an orthopedics ward in each teaching hospital, even then almost all types of trauma cases, such as, road traffic accidents, homicidal injuries, industrial injuries, accidental fall injuries due to violence are admitted in this hospital every day.

Road traffic accident is a global problem. In the present century it represents, a major epidemic of non-communicable disease with resultant disability and handicap. Previously it was thought to be a problem of Western countries, now it is a big concern of the developing country as well. Accidents have their own natural history and follow the same epidemiological pattern as that of other diseases. A risky mix of vehicles in the traffic stream, defective roads with poor street lighting, defective layout of cross roads, poor road environment with almost no segregation of 
pedestrians from wheeled traffic, overloading of transports lead to the accidents which caused human suffering and economic loss due to disabilities.

The total cost of RTA due to direct cost for treatment purpose and indirect cost due to daily wedge losses, economic loss, familial loss and social burden together produce significant impact on the economy of our country. Sincere efforts should be taken to reduce these unwanted events. Therefore RTA is a subject to be highlighted rather than neglected. As the sample size was small and conducted in one tertiary hospital, further comprehensive study should be undertaken to identify the economic impact of road traffic accident in Bangladesh.

\section{References}

1. World Report on Road Traffic Injury Prevention: Summary -Google Books Result. Available at: books.google.com / books?isbn $=1437904068 \ldots$ Marjorie Peden - 2008.

2. Anonymous. Emergency care for accident victims. WHO Chron 1969; 23: 137.

3. Anonymous. Accidents. WHO Chron 1967;21:356.
4. Road traffic injuries. www.who.int. WHO World Remembrance Day for road traffic victims 15 November 2009, Global status report on road safety.

5. Accident Research Centre ARC-BUET, Dhaka.

6. Islam AJames P Grant School of Public Health, BRAC University, Dhaka-RTAs and our healthcare system.

7. Hossain Amjad Md et al :Pattern of Injury and Outcome of patients admitted in a casualty unit Dhaka Medical College Hospital; The Journal of Bangladesh Orthopaedic Society Jan' 1991 \&92. Vol-6, \&7 37-41.

8. Md. Qavi lqbal Md. Amjad Hossain: An overview of road traffic accidents in Bangladesh-A study at RIHD : the Journal of Bangladesh Orthopedic Society , Jan1996, vol-11 Nol:1.

9. Anwaruzzaman AKM, Mostafa MD, Saluddin AKM.A hospital based epidemiological study on road accidents. Bangladesh Med J 1987; 16:76-81.

10. Altes AG, Perez k - The economic cost of road traffic crashes in an urban setting; UKPMC Article -UK Publication Page: 1.

11. Reddy G.M.M, Negandhi H, Singh D, et al - Extent and determinants of cost of road traffic injuries in an Indian city-volume 63 , page -2 .

12. Mishral B, Sinha N D, Sukhla SK, Sinha AK Epidemiological study of road traffic accident cases from Western Nepal Med 19 April 2010.

13. Hoque MM, Mahmud S M S, Paul S-Cost of RTA in Bangladesh. 